\title{
Impact of high-fat overfeeding on white adipose tissue and systemic metabolic and inflammatory responses
}

\author{
Rebecca Dewhurst-Trigg, Rachel M. Woods, Carl J. Hulston and Oonagh Markey \\ Loughborough University, Loughborough, United Kingdom
}

\section{Abstract}

White adipose tissue (WAT) inflammation is linked to the development of cardiometabolic disease. A high intake of saturated fatty acids (SFA) may promote a more pro-inflammatory WAT gene expression profile, compared to monounsaturated fatty acids ${ }^{(1,2)}$. This is concerning as the UK adult population currently exceeds the SFA intake target of $<10 \%$ total energy (TE), at $11.9 \% \mathrm{TE}^{(3)}$. However, further research is needed to understand how SFA ingestion impacts the protein content and phosphorylation of key targets involved in WAT inflammatory signalling. Therefore, this study investigated the effect of short-term, high-fat overfeeding on WAT and systemic metabolic and inflammatory responses in healthy, non-obese individuals.

Fifteen (9 men, 6 women) apparently healthy participants (mean (SE) age; $26.6(1.2)$ y, BMI; $24.4(0.6) \mathrm{kg} / \mathrm{m}^{2}$ ) consumed a high-fat (dietary target: $65.0 \% \mathrm{TE}$ total fat; $32.5 \% \mathrm{TE}$ SFA), high-calorie (+ $50 \%$ estimated energy requirements) diet for 7 days. Fasted venous blood and WAT samples were collected pre- and post-intervention.

Body mass increased following the intervention (pre-intervention vs. post-intervention: $75.2(2.9) \mathrm{kg}$ vs. $76.4(2.9) \mathrm{kg} ; P<0.0001)$. The intervention also led to increases in glucose $(4.4(0.1)$ vs. $4.6(0.1) \mathrm{mmol} / \mathrm{L} ; P=0.022)$ and lipopolysaccharide-binding protein (12.9 (1.3) vs. $17.7(3.0) \mu \mathrm{g} / \mathrm{mL} ; P=0.038)$, and a decrease in triacylglycerol $(0.91(0.08)$ vs. $0.72(0.05) \mathrm{mmol} / \mathrm{L} ; P=0.007)$. Insulin, IL-6 and soluble CD14 concentrations remained unchanged (all $P>0.05$ ). At the WAT level, total protein (TLR4;

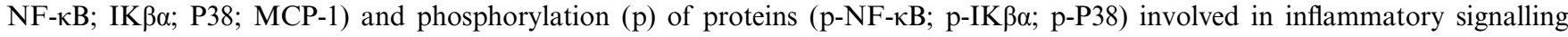
were unchanged following the intervention (all $P>0.05$ ).

In conclusion, although short-term, high-fat overfeeding led to an increase in body mass as well as systemic metabolic alterations, the content and phosphorylation of proteins involved in WAT inflammatory signalling were unaltered in healthy, non-obese individuals. Further analysis will reveal the impact of high-fat overfeeding on peripheral blood monocyte populations, which are involved in mediating pro- and anti-inflammatory responses.

This research was supported by a Society for Endocrinology Early Career Grant.

\section{Conflict of Interest}

There is no conflict of interest.

\section{References}

1. Finucane OM, Lyons CL, Murphy AM et al.. (2015) Diabetes 64, 2116-2128.

2. van Dijk SJ, Feskens EJM, Bos MB et al.. (2009) Am J Clin Nutr 90, 1656-1664.

3. National Diet and Nutrition Survey (2018) Results from Years 7 and 8 (combined) of the rolling programme (2014/2015 to 2015/2016). London. Available from: https://www.gov.uk/government/statistics/ndns-results-from-years-7-and-8-combined [Accessed 04 April 2019] 